\title{
Probing the Methyl Torsional Barriers of the $E$ and $Z$ Isomers of Butadienyl Acetate by Microwave Spectroscopy
}

\begin{abstract}
Atef Jabri, ${ }^{[a]}$ Vinh Van, ${ }^{[b]}$ Ha Vinh Lam Nguyen, ${ }^{*}{ }^{[a]}$ Wolfgang Stahl, ${ }^{[b]}$ and Isabelle Kleiner ${ }^{[a]}$
Abstract: The Fourier transform microwave spectra of the $E$ and the $Z$ isomer of butadienyl acetate were measured in the frequency range from 2 to $26.5 \mathrm{GHz}$ under molecular jet conditions. The most stable conformer of each isomer, in which all heavy atoms are located in a symmetry plane, was identified after analyzing the spectrum by comparison with the results from quantum chemical calculations. The barriers to internal rotation of the acetyl methyl group are $149.1822(20) \mathrm{cm}^{-1}$ and $150.2128(48) \mathrm{cm}^{-1}$ for the $E$ and

This induces our interest to study butadienyl acetate, aiming to answer the following questions: (i) Is there a further increase in the torsional barrier of the acetyl methyl group, when the number of conjugated double bonds is increased? (ii) Butadienyl acetate exists as an $E$ and a $Z$ isomer. Are the barrier heights significantly different in these isomers? (iii) Is there a correlation of the torsional barrier with the infrared $\mathrm{C}=\mathrm{O}$ stretching vibration?
\end{abstract} the $Z$ isomer, respectively, and are similar to that of vinyl acetate. A comparison between two theoretical approaches treating internal rotations, the rho axis method and combined axis method, is also performed. The influence of the alkyl chain $R$ on the methyl torsional barriers in acetates $\mathrm{CH}_{3}-\mathrm{COO} R$ is discussed.

\section{Introduction}

During several years we study the barriers to internal rotation of the acetyl methyl group in acetates (acetic acid esters), $\mathbf{C H}_{3}-$ COOR. So far, we found that all acetates can be divided into three classes. Class I contains $\alpha, \beta$-saturated acetates, where the torsional barrier is always close to $100 \mathrm{~cm}^{-1}$. Examples are methyl acetate,,$^{[1]}$ ethyl acetate, ${ }^{[2]}$ n-propyl acetate, ${ }^{[3]}$ three conformers of $n$-butyl acetate, ${ }^{[4]}$ two conformers of $n$-pentyl acetate,$^{[5]} \mathrm{n}$-hexyl acetate, ${ }^{[6]}$ and allyl acetate. ${ }^{[7]}$ Even if the alkyl chain is branched as in the case of isopropyl acetate ${ }^{[8]}$ and isoamyl acetate, ${ }^{\left[{ }^{9]}\right.}$ the barrier height seems to be almost unaffected. It is plausible that conjugation within the ester group is responsible for the relatively low barrier. Class II contains $\alpha, \beta$ unsaturated acetates where the $\mathrm{C}=\mathrm{C}$ double bond is located in the COO plane. Extended conjugation over this bond is possible and increases the barrier to $150 \mathrm{~cm}^{-1}$. Vinyl acetate is the only example in this class. ${ }^{[10,11]}$ Finally, class III comprises $\alpha, \beta$ unsaturated acetates where the double bond is not located in the COO plane. Here, the extended conjugation is not as effective as in the case of class II, because the conjugated system would not be planar. Two representatives of class III are isopropenyl acetate ${ }^{[12]}$ and phenyl acetate, ${ }^{[13]}$ in which we observed barrier heights around $135 \mathrm{~cm}^{-1}$. All molecules are summarized in Figure 1. However, with only one example in class II, the data set is not sufficient for a definitive statement.

[a] A. Jabri M.Sc., Dr. H. V. L. Nguyen, Dr. I. Kleine

Laboratoire Interuniversitaire des Systèmes Atmosphériques (LISA) CNRS UMR 7583, Université Paris-Est Créteil, Université Paris Diderot, 61 avenue du Général de Gaulle, F-94010 Créteil cedex, France.

E-mail: lam.nguyen@lisa.u-pec.fr

[b] V. Van M.Sc., Prof. Dr W. Stah Institute of Physical Chemistry RWTH Aachen University Landoltweg 2, D-52074 Aachen, Germany

Supporting information for this article is given via a link at the end of the document.

\section{Quantum Chemical Calculations}

\subsection{Conformational analysis}

The $E$ and the $Z$ isomer of butadienyl acetate (depicted as (11) and (12), respectively, in Figure 1) are converted into each other by a rotation of $180^{\circ}$ about the $\mathrm{C}_{8}-\mathrm{C}_{10}$ double bond (for atom numbering see Figure 2). For each of these isomers, different conformations can be created by choosing the dihedral angles $\varphi_{1}=\angle\left(\mathrm{C}_{3}-\mathrm{C}_{1}-\mathrm{O}_{7}-\mathrm{C}_{8}\right)$, $\varphi_{2}=\angle\left(\mathrm{C}_{1}-\mathrm{O}_{7}-\mathrm{C}_{8}-\mathrm{C}_{10}\right)$, and $\varphi_{3}=\angle\left(\mathrm{C}_{8}-\mathrm{C}_{10}-\mathrm{C}_{12}-\mathrm{C}_{14}\right)$ to be $0^{\circ}$ or $180^{\circ}$, corresponding to the rotations about the $\mathrm{C}_{1}-\mathrm{O}_{7}, \mathrm{O}_{7-}$ $\mathrm{C}_{8}$, and $\mathrm{C}_{10}-\mathrm{C}_{12}$ bonds. Optimizations at the MP2/6$311++G(d, p)$ level of theory using the GAUSSIAN program package ${ }^{[14]}$ yield six and five conformers for the $E$ and the $Z$ isomer, respectively. Harmonic frequency calculations confirm that they are all stable conformers rather than saddle points. The rotational constants, energies relative to the lowest energy conformer, as well as the optimized dihedral angles $\varphi_{1}, \varphi_{2}$, and $\varphi_{3}$ of all conformers are listed in Table S-1 of the Supporting Information (SI). All conformers are depicted in Figure S-F1 of the SI.

The rotation about the $\mathrm{C}_{1}-\mathrm{O}_{7}$ bond results in trans and cis ester configurations. In agreement with our previous investigations ${ }^{[1-10,13,14]}$ and results from quantum chemical calculations, ${ }^{[16]}$ cis esters are stable conformations; on the other hand they possess much higher relative energy than those of trans esters and cannot be observed under our molecular jet conditions. Therefore, we only focus on trans esters in the present study. It should be noted that we define the trans esters as illustrated in Figure 1, where the carbon chain is in trans position to the acetyl methyl group.

The energetically most favorable conformer of the $E$ and the $Z$ isomer are illustrated in Figures 2 and 3 , respectively, which will be named in short the $E$ and the $Z$ isomer from now on. The $a b$ initio predicted rotational constants of the $E$ isomer are $A=8.302 \mathrm{GHz}, B=0.776$ $\mathrm{GHz}$, and $C=0.714 \mathrm{GHz}$. Noticeable is the high dipole moment component of $1.98 \mathrm{D}$ in $b$-direction, which suggests a microwave spectrum with intense $b$-type transitions. The dipole moment component in a-direction is $0.47 \mathrm{D}$, i.e. atype transitions are also present in the spectrum. 
Class I<smiles>COC(C)=O</smiles><smiles>CCOC(C)=O</smiles>

(1) $102.413(20)$

(2) $101.606(23)$

(3) $103.341(18)$<smiles>CCCCCOC(C)=O</smiles>

(4) $99.66(36)$

(5) $102.4646(39)$<smiles>CCCCCCOC(C)=O</smiles>

(6) $99.759(28)$<smiles>CC(=O)OC(C)C</smiles>
(7) $97.911(20)$

(8) $93.98242(93)$<smiles>C=CCOC(C)=O</smiles>

(9) $98.093(12$<smiles>CCC(C)COC(C)=O</smiles>

Class II<smiles>C=COC(C)=O</smiles>

(10) $151.492(34)$
Class III

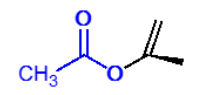

(13) $135.3498(38)$<smiles>C=C/C=C/OC(C)=O</smiles>

(11) $150.2128(48)$<smiles>C=C/C=C\OC(C)=O</smiles>

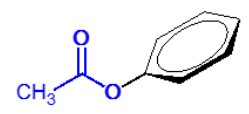

(14) $138.22(90)$
Figure 1. Torsional barriers of the acetyl methyl groups in acetates (in $\mathrm{cm}^{-1}$ ). Class I: (1) Methyl acetate, ${ }^{[1]}$ (2) ethyl acetate, ${ }^{[2]}$ (3) n-propyl acetate, ${ }^{[3]}$ (4) nbutyl acetate, ${ }^{[4]}(5)$ n-pentyl acetate, ${ }^{[5]}(6)$ n-hexyl acetate, ${ }^{[6]}(7)$ isopropyl acetate,$^{[8]}(8)$ isoamyl acetate, ${ }^{[9]}$ and (9) allyl acetate. ${ }^{[7]}$ Class II: (10) Vinyl acetate, ${ }^{[10,11]}$ (11) $E$ butadienyl acetate (this work), and (12) $Z$ butadienyl acetate (this work). Class III: (13) Isopropenyl acetate ${ }^{[12]}$ and (14) preliminary results of phenyl acetate. ${ }^{[13]}$

In contrast to our chemical intuition, which assumes a completely planar structure as the energetically favorable conformation, the optimized geometry predicts that the butadienyl group is slightly tilted out of the $\mathbf{C H}_{3}-\mathrm{COO}$ plane by an angle of $11^{\circ}$, as can be recognized in the lower panel of Figure 2. This is the reason for a dipole moment component of $0.27 \mathrm{D}$ in $c$-direction, with the equilibrium configuration being chiral. As we shall see in the discussion, the experimental results are helpful in this case to assess this observation from quantum chemical calculations.

For the $Z$ isomer, the predicted rotational constants are $A=5.820 \mathrm{GHz}, B=0.922 \mathrm{GHz}$, and $C=0.804 \mathrm{GHz}$; the dipole moment components are calculated to be $\mu_{a}=0.41 \mathrm{D}$ $\mu_{b}=1.95 \mathrm{D}$, and $\mu_{c}=0.38 \mathrm{D}$. Also in this isomer, a tilt angle of $12^{\circ}$ is predicted for the butadienyl group (see the lower panel of Figure 3). The atomic coordinates of both conformers in the principal axis system are available in Table S-2 in the SI.

\subsection{Basis Set Variation}

The Møller-Plesset perturbation theory of second order (MP2) and density functional theory (DFT) methods in combination with different basis sets were used to reoptimize the geometry of the $E$ and the $Z$ isomer given in Figures 2 and 3, respectively.

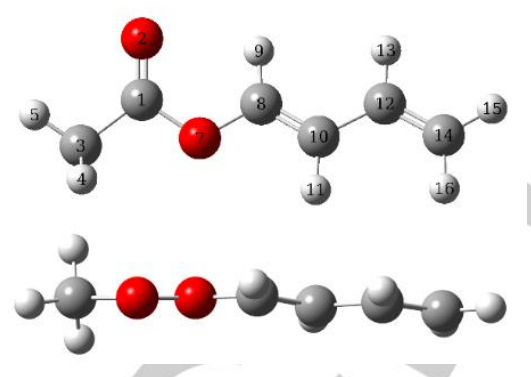

Figure 2. The energetically most favorable conformer of the $E$ isomer of butadienyl acetate optimized at the MP2/6-311++G(d,p) level of theory.

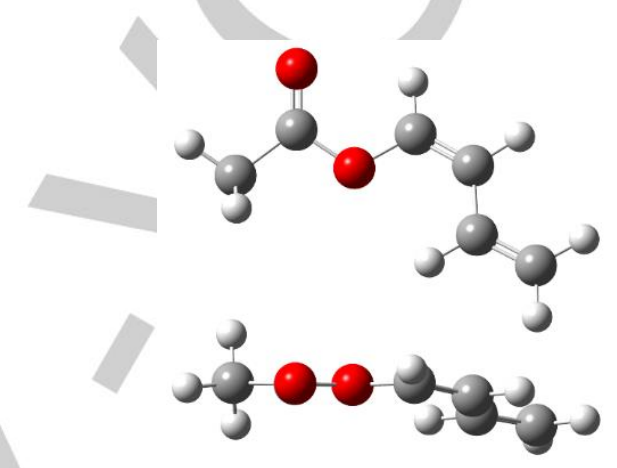

Figure 3. The energetically most favorable conformer of the $Z$ isomer of butadienyl acetate optimized at the MP2/6-311++G(d,p) level of theory. The atom are numbered as in Figure 2.

Since calculations at the MP2/6-311++G(d,p) level indicate that the butadienyl group is slightly tilted out of the $\mathrm{CH}_{3}$ COO plane, whereas our chemical intuition assumes a completely planar structure, the basis set variation helps to check for convergence and to find out whether this behavior also occurs at other levels of theory. Moreover, the calculated rotational constants will be compared with the experimental values. The results will be discussed in section 4 . The calculated rotational constants are collected in Table S-3 in the SI.

\subsection{Internal Rotation}

The acetyl methyl group in butadienyl acetate undergoes internal rotation and causes all rotational lines in the microwave spectrum to split into an $A$ and an $E$ component. ${ }^{[16]}$ The barriers to internal rotation are calculated to be $124 \mathrm{~cm}^{-1}$ and $119 \mathrm{~cm}^{-1}$ for the $E$ and the $Z$ isomer, respectively, by optimizing the transition state of the methyl group rotation using the Berny algorithm ${ }^{[17]}$ at the MP2/6-311++G(d,p) level of theory. The calculations were repeated for other combinations of methods and basis sets given in section 2.2. The results are also listed in Table S-3. 


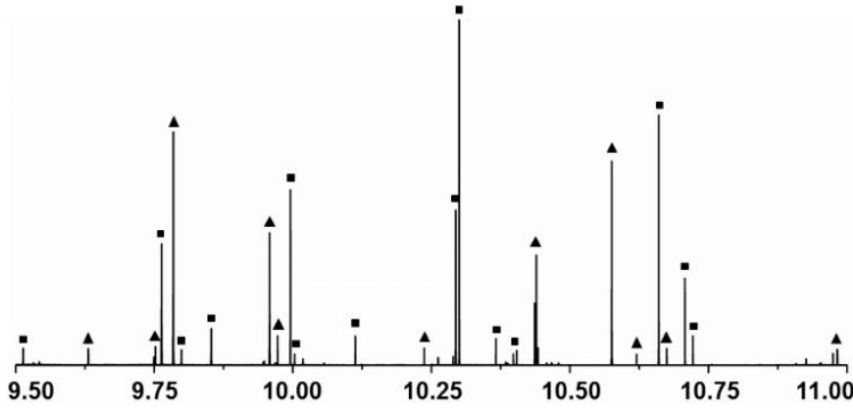

Figure 4. A portion of the broadband scan between 9.5 and $11.0 \mathrm{GHz}$ obtained by automatically recorded spectra in a step width of $0.25 \mathrm{MHz}$. ( $\Delta$ ) $E$ isomer, ( $\mathbf{\square}) Z$ isomer.

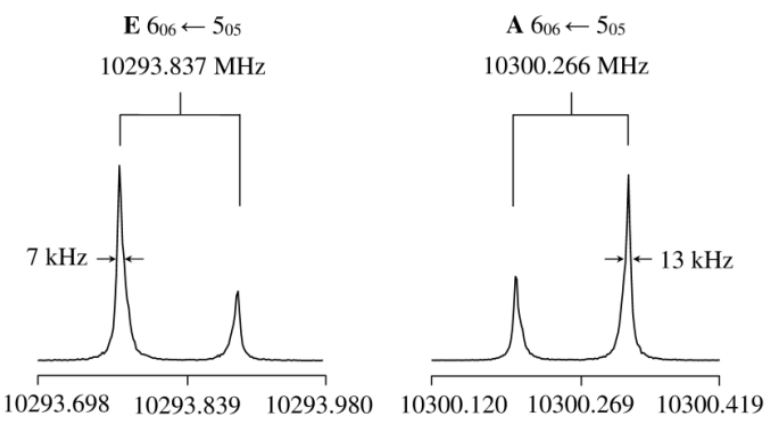

Figure 5. A typical $A$ and $E$ species spectrum (frequencies in $\mathrm{MHz}$ ) of the $6_{0}$ $\leftarrow 505$ transition of the $Z$ isomer of butadienyl acetate. For each spectrum, 50 decays were co-added.

\section{Microwave Spectroscopy}

\subsection{Measurements}

A broadband scan was recorded in the frequency range from 8.0 to $13.3 \mathrm{GHz}$, where overlapping spectra were automatically taken in a step width of $0.25 \mathrm{MHz}$. Figure 4 illustrates a portion of this scan between 9.5 and $11.0 \mathrm{GHz}$. For each spectrum, 50 free polarization decays were coadded. The broadband scan indicates roughly the line positions. To obtain frequencies with high accuracy, all lines were remeasured with more co-added decays. After Fourier transformation they appeared as doublets because of the Doppler effect. Figure 5 shows an example of an A and an E species transition measured at high resolution, with the Doppler pair marked by brackets. The measurement accuracy is $2 \mathrm{kHz}$.

\subsection{Spectral Assignment}

Quantum chemical calculations have shown that the $Z$ isomer has smaller rotational constants than the $E$ isomer. Therefore, we began our assignment with the spectrum of the $Z$ isomer, because transitions with lower $J$ are present in the broadband scan, which might simplify the assignment.

\subsection{1. $Z$ Isomer}

As a first step, we neglected the methyl internal rotation and treated butadienyl acetate as an effective rigid-rotor. Though the dipole moment component in a-direction was calculated to be much smaller than that in $b$-direction, we still began with searching for a-type transitions due to their characteristic pattern, which can be often assigned readily in the spectrum. Using the rotational constants calculated at the MP2/6-311++G(d,p) level, a theoretical spectrum between 8 and $13 \mathrm{GHz}$ was predicted using the program $X I A M{ }^{[18]}$ and compared to the experimental broadband scan mentioned in section 3.1. The very intense $R$-branch $J$ $=6 \leftarrow 5$ and $7 \leftarrow 6$ a-type transitions with $K_{\mathrm{a}}=0$ and 1 were firstly identified in the scan, yielding the $B$ and $C$ rotational constants. Afterwards, $b$-type transitions were also assigned, which fixed the $A$ rotational constant. This enabled us to predict the whole rigid-rotor spectrum with sufficient accuracy to find all remaining $A$ species lines in the frequency range from $2-26.5 \mathrm{GHz}$. At this stage, 134 lines were fitted with the three rotational constants $A, B, C$ and five quartic centrifugal distortion constants.

As a next step, we took into account the methyl internal rotation and predicted both, the $A$ and $E$ species transitions. The initial $V_{3}$ potential was taken from that found in vinyl acetate; ${ }^{[10]}$ the angle between the internal rotor axis and the principal $a$-axis was taken from $a b$ initio result at the MP2/6-311++G(d,p) level. The rotational constant of the methyl group $F_{0}$ was fixed to $158 \mathrm{GHz}$, which we considered to be a reasonable value also found in other acetates. By comparing the theoretical and experimental broadband scan, the assignment was straightforward for the a-type $R$-branch transitions mentioned above, where the A$\mathrm{E}$ splittings were less than $10 \mathrm{MHz}$. The assignment of $b$ type lines with much larger splittings was more difficult. However, it was finally successful by trial and error. In total, $134 \mathrm{~A}$ species and $140 \mathrm{E}$ species lines were fitted using the program XIAM with a root mean square (rms) deviation of $15.4 \mathrm{kHz}$.

The molecular parameters are summarized in Table 1. A list including all fitted transitions is given in Table $\mathrm{S}-4 \mathrm{a}$ in the SI.

\subsection{2. $E$ Isomer}

After the $Z$ isomer was assigned, a large number of lines remained in the scan, which belong to the $E$ isomer. We used the same a-type $R$-branch transitions mentioned in section 3.2.1. for the assignment process, which could also be readily identified here. The assignment of $b$-type transitions was more difficult than in the case of the $Z$ isomer, because the $A$ rotational constant of the $E$ isomer is much larger. Nevertheless, after the b-type $R$-branch transitions $2_{12} \leftarrow 1_{01}, 3_{13} \leftarrow 202$, and $4_{14} \leftarrow 3_{03}$ were assigned, we could measure and fit $79 \mathrm{~A}$ species and $92 \mathrm{E}$ species transitions up to $J=15$ with the program $X I A M$ to a rms deviation of $7.8 \mathrm{kHz}$. 
Table 1. Molecular parameters of the $E$ and $Z$ isomers of butadienyl acetate in the principal axis system obtained by the programs XIAM and BELGI- $C_{s}$.

\begin{tabular}{|c|c|c|c|c|}
\hline \multirow[t]{2}{*}{ Par. [a] } & \multicolumn{2}{|l|}{$Z$ isomer } & \multicolumn{2}{|l|}{$E$ isomer } \\
\hline & $X I A M$ & $B E L G I-C_{s}$ & $X I A M$ & $B E L G I-C_{s}$ \\
\hline$A / M H z$ & $5891.230(22)$ & $5874.25(20)$ & $8408.726(17)$ & $8375.05(11)$ \\
\hline $\mathrm{B} / \mathrm{MHz}$ & $924.6574(22)$ & $923.643(31)$ & $778.1573(11)$ & $778.59948(82)$ \\
\hline $\mathrm{C} / \mathrm{MHz}$ & $803.8922(19)$ & $804.293(27)$ & $715.8163(11)$ & $716.08363(37)$ \\
\hline$D J / k H z$ & $0.06520(70)$ & $0.22883(53)$ & $0.01567(51)$ & $0.014114(99)$ \\
\hline$D_{J K} / k H z$ & $-0.7484(83)$ & & $0.5414(90)$ & \\
\hline$D_{K} / k H z$ & $9.24(21)$ & & $5.87(36)$ & \\
\hline$d_{1} / k H z$ & $-0.01394(37)$ & & $-0.00109(13)$ & \\
\hline $\mathrm{d}_{2} / \mathrm{kHz}$ & $-0.00148(13)$ & & $0.0^{\mathrm{b}}$ & \\
\hline$V_{3} / \mathrm{cm}^{-1}$ & $150.2128(48)$ & $148.165(60)$ & 149.1822(20) & $149.2732(67)$ \\
\hline$F_{0}^{[b]} / G H z$ & 158.0 & & 158.0 & \\
\hline $\mathrm{F} / \mathrm{GHz}$ & $160.1^{[c]}$ & $160.1^{[d]}$ & $163.5^{\mathrm{c}}$ & $163.5^{[\mathrm{d}]}$ \\
\hline$s^{[e]}$ & 12.50073 & 12.3303 & 12.15694 & 12.16422 \\
\hline$I_{\alpha}[\mathrm{c}] / \mathrm{u} \AA^{2}$ & 3.1986 & & 3.1986 & \\
\hline$\Delta_{d} / \mathrm{u} \AA^{2}$ & -3.6779 & -4.8395 & -3.5401 & \\
\hline$(i, a)^{/}$ & $61.1753(64)$ & $61.21784(19)$ & $39.5131(20)$ & 39.4542 \\
\hline$(i, b) /^{\circ}$ & $28.8247(26)$ & $28.78216(71)$ & $50.4869(20)$ & $50.54578(59)$ \\
\hline$(i, c) /^{\circ}$ & $90.0^{[b]}$ & $90.0^{[b]}$ & $90.0^{[b]}$ & $90.0^{[b]}$ \\
\hline$D_{\text {piz }} / \mathrm{kHz}$ & $31.10(26)$ & & $20.89(16)$ & \\
\hline$D_{\text {pizK }} / M H z$ & $-0.7209(33)$ & & -2.0362( & \\
\hline$D_{\text {pi2- }} / k H z$ & $5.23(17)$ & & $3.725(51)$ & \\
\hline $\mathrm{N}^{[e]}$ & $134 / 140$ & $134 / 140$ & $79 / 92$ & $79 / 92$ \\
\hline$\sigma^{[9] /} / \mathrm{kHz}$ & 15.4 & 2.1 & 7.8 & 1.4 \\
\hline
\end{tabular}

[a] All parameters refer to the principal axis system. Watson's $S$ reduction in $I^{r}$ representation was used. ${ }^{[b]}$ Fixed value. ${ }^{[c]}$ Derived parameter from $F_{0}$. [d] Fixed to the value of the $X I A M$ fit. ${ }^{[e]}$ Reduced barrier, defined as $s=4 V_{3} / 9 F$. ${ }^{[t]}$ Number of the $A$ and $E$ species lines $\left(\mathrm{N}_{\mathrm{A}} / \mathrm{N}_{\mathrm{E}}\right)$. ${ }^{[\mathrm{g}]}$ Root-mean-square deviation of the fit.

\subsubsection{Fits}

The program XIAM was used to fit the microwave spectra of the $E$ and the $Z$ isomer of butadienyl acetate to a rms deviation of $7.8 \mathrm{kHz}$ and $15.4 \mathrm{kHz}$, respectively, which is much larger than the measurement accuracy $(2 \mathrm{kHz})$. From our previous investigations on acetates, we know that $E$ species transitions are often not well fitted, probably due to the low barrier to internal rotation of the acetyl methyl group. No higher order coupling terms between the internal rotation and the overall rotation can be easily implemented to improve the fit quality.

As an alternative, a global fit with the program BELGI$C_{s}$ was carried out. A comparison of the two programs was described elsewhere and will not be repeated here. ${ }^{[2,10]}$ The same data sets of both, the $E$ and $Z$ isomers, were fitted to measurement accuracy with rms deviations of $1.4 \mathrm{kHz}$ and $2.1 \mathrm{kHz}$, respectively. Parameters, which can be transformed into the principal axis system by a rotation about the $c$-axis, are given in Table 1; all BELGI-Cs parameters in the rho axis system in Table 2. All fitted transitions along with their residuals are listed in Table S-4b.

Table 2. Spectroscopic constants of the $E$ and the $Z$ isomer of butadieny acetate in the rho axis system obtained with the program BELGI-Cs.

\begin{tabular}{|c|c|c|c|c|}
\hline Operator ${ }^{[a]}$ & $P^{[b]}$ & Unit & $Z$ isomer ${ }^{[c]}$ & $E$ isomer ${ }^{[c]}$ \\
\hline $\mathbf{P a}^{2}$ & $A$ & $\mathrm{MHz}$ & $5499.39(18)$ & $8330.84(11)$ \\
\hline $\mathbf{P}_{\mathrm{b}}{ }^{2}$ & $B$ & $\mathrm{MHz}$ & $1298.502(11)$ & $716.08362(37)$ \\
\hline $\mathbf{P}_{\mathrm{c}}{ }^{2}$ & $C$ & $\mathrm{MHz}$ & $804.29343(44)$ & $822.8098(14)$ \\
\hline$\left\{\mathbf{P}_{\mathrm{a}}, \mathbf{P}_{\mathrm{b}}\right\}$ & $D_{\mathrm{ab}}$ & $\mathrm{GHz}$ & $1.309680(18)$ & $0.5778299(78)$ \\
\hline$-\mathbf{P}^{4}$ & $D_{J}$ & $\mathrm{kHz}$ & $0.22883(53)$ & $0.014114(99)$ \\
\hline$-\mathbf{P}_{\mathrm{a}}^{4}$ & $D_{K}$ & $\mathrm{kHz}$ & $14.112(49)$ & $5.956(72)$ \\
\hline$-\mathbf{P}^{2} \mathbf{P}^{2}$ & $D_{J K}$ & $\mathrm{kHz}$ & $-4.421(15)$ & $0.3601(22)$ \\
\hline$-2 \mathbf{P}^{2}\left(\mathbf{P}_{b}{ }^{2}-\mathbf{P}_{c}{ }^{2}\right)$ & $d\lrcorner$ & $\mathrm{kHz}$ & $0.09471(28)$ & $0.0^{[\mathrm{d}]}$ \\
\hline$-\left\{\mathbf{P}_{\mathrm{a}^{2}},\left(\mathbf{P}_{\mathrm{b}}{ }^{2}-\mathbf{P}_{\mathrm{c}}{ }^{2}\right)\right\}$ & $d k$ & $\mathrm{kHz}$ & $-0.4234(23)$ & $0.2129(98)$ \\
\hline $\mathbf{P}_{\alpha}^{2}$ & $F$ & $\mathrm{~cm}^{-1}$ & $5.341^{[\mathrm{e}]}$ & $5.454^{[\mathrm{e}]}$ \\
\hline$(1 / 2)(1-\cos 3 \alpha)$ & $V_{3}$ & $\mathrm{~cm}^{-1}$ & $148.165(60)$ & $149.2732(67)$ \\
\hline $\mathbf{P}_{\mathrm{a}} \mathbf{P}_{\alpha}$ & $\rho$ & & $0.018011(20)$ & $0.0412437(49)$ \\
\hline$(1-\cos 3 \alpha) \mathbf{P}^{2}$ & $F_{\mathrm{v}}$ & $\mathrm{MHz}$ & $-0.8253(17)$ & $-0.9747(12)$ \\
\hline$(1-\cos 3 \alpha) \mathbf{P a}^{2}$ & $k_{5}$ & $\mathrm{MHz}$ & $49.14(62)$ & $72.23(38)$ \\
\hline$\left\{\mathbf{P}_{\mathrm{a}}, \mathbf{P}_{\mathrm{b}}\right\} \mathbf{P}_{\alpha}^{2}$ & $\Delta \mathrm{ab}$ & $\mathrm{MHz}$ & $-0.24516(34)$ & $0.0^{d}$ \\
\hline$\left\{\mathbf{P}_{\mathrm{a}}, \mathbf{P}_{\mathrm{b}}\right\} \mathbf{P}_{\mathrm{a}} \mathbf{P}_{\alpha}$ & $\delta_{\mathrm{ab}}$ & $\mathrm{kHz}$ & $4.45(35)$ & $0.0^{d}$ \\
\hline $\begin{array}{l}(1-\cos 3 \alpha)\left(\mathbf{P}_{b}{ }^{2}-\right. \\
\left.\mathbf{P}_{c}^{2}\right)\end{array}$ & $C_{2}$ & $\mathrm{MHz}$ & $0.0^{d}$ & $-0.41694(43)$ \\
\hline
\end{tabular}

[a] All constants refer to the rho axis system. Therefore, the inertia tensor is not diagonal and the constants cannot be directly compared to those referring to the principal axis system. $\mathbf{P}_{\mathrm{a}}, \mathbf{P}_{\mathrm{b}}$, and $\mathbf{P}_{\mathrm{c}}$ are the components of the overall rotational angular momentum. $\mathbf{P}_{\alpha}$ is the angular momentum of the internal rotor rotating around the internal rotor axis by an angle $\alpha .\{u, v\}$ is the anticommutator uv $+\mathrm{vu} .{ }^{\mathrm{b}}$ Parameters. The product of the parameter and operator from a given row yields the term actually used in the vibration-rotation-torsion Hamiltonian, except for $F, \rho$, and $A$, which occur in the Hamiltonian in the form $F\left(\mathbf{P}_{\alpha^{-}} \rho \mathbf{P}_{\mathrm{a}}\right)^{2}+A \mathbf{P}_{\mathrm{a} .}{ }^{[c]}$ Values of the parameters from the present fit. Statistical uncertainties are shown as one standard uncertainty in unit of the last digit. [d] Set to zero. ${ }^{[\mathrm{e}]}$ Fixed to the value obtained from the XIAM fit (see Table 1). 


$$
\mathrm{CH}_{\mathrm{O}}^{\mathrm{O}} \leftrightarrow \mathrm{CH}_{\mathrm{O}}
$$

(a)<smiles>CCOC(C)=O</smiles>

(b)<smiles>C=COC(C)=O</smiles>

(c)<smiles>C=CC=COC(C)=[O+]C=CC=C</smiles>

(d)

Figure 6. Mesomerism of the acetate anion (a), ethyl acetate (b), vinyl acetate (c), and butadienyl acetate (d).

\section{Discussion}

The BELGI- $C_{s}$ fit improves the rms deviations for the $E$ and the $Z$ isomer of butadienyl acetate to measurement accuracy, and provides better predictive power than the $X I A M$ fit. However, for assignment purposes the program $X I A M$ is more convenient to use.

The torsional barrier of the acetyl methyl group is essentially the same in both isomers, which is $149.1822(20)$ $\mathrm{cm}^{-1}$ and $150.2128(48) \mathrm{cm}^{-1}$ for the $E$ and the $Z$ isomer, respectively, according to the XIAM fits. The values obtained by $B E L G I-C_{s}$ agree within $1.4 \%$. The reduced barriers $s=4 V_{3} / 9 F$ as well as the methyl rotor angles in the $B E L G I-C_{s}$ and the XIAM fits are also very similar (see Table 1). It should be noted that with both programs, a strong correlation between $V_{3}$ and $l_{\alpha}$ is present, because only transitions in the ground torsional state are included in the analysis. Therefore, we fixed $l_{\alpha}$ to a reasonable value found in other acetates.

Geometry optimizations of both, the $E$ and the $Z$ isomer, have shown that the butadienyl group is slightly tilted out of the plane of the ester group. Therefore, referred to the equilibrium geometry they exist as pairs of enantiomers. Moreover, a non-vanishing dipole moment component in the $c$-direction is predicted. We note that some $c$-type transitions can be found in the frequency lists (Table S-4), which are all E species lines. It is known that for the $\mathrm{E}$ species, forbidden transitions can be observed, as found in e.g. ethyl acetate ${ }^{[2]}$ and vinyl acetate. ${ }^{[10]}$ On the other hand, despite carefully searching for A species $c$-type transitions, none of them were found. This discrepancy might be due to following reasons: (i) There is indeed a dipole moment in $c$-direction but our sensitivity is too small to detect the weak $c$-type lines. (ii) The enantiomers are separated by a low barrier and the tunneling ground state is above this barrier causing an effective $\mathrm{C}_{\mathrm{s}}$ geometry. In this case the expectation value of the dipole moment in $c$ direction would be zero.

The support for an effective $\mathrm{C}_{\mathrm{s}}$ symmetry is that the fit achieved with $B E L G I-C_{s}$, which reproduced the experimental data within measurement accuracy, did not require any out-of-plan terms. Finally, the inertial defect $\Delta_{c}=$ $I_{c}-I_{a}-I_{b}$ of $-3.540 u \AA^{2}$ and $-3.680 u \AA^{2}$ of the $E$ and the $Z$ isomer, respectively, confirms that the heavy atom skeleton is planar. This value is almost the same as that found in other related molecules containing a pair of out-of-plane hydrogen atoms, e.g. methyl vinyl ketone $\left(\Delta_{c}=-3.162\right.$ $\left.\mathrm{u} \AA^{2}\right)^{[19]}$ and vinyl acetate $\left(\Delta_{c}=-3.491 \mathrm{u} \AA^{2}\right){ }^{[10]}$

We only find the $\mathrm{C}_{1}$ molecular structures in calculations at five levels of theory: $M P 2 / 6-31+G(d, p)$, MP2/6-31++G(d,p), MP2/6-311+G(d,p), MP2/6$311++G(d, p)$, and $C C S D / 6-311++G(d, p)$, which indicates that the combination of diffusion functions, $(d, p)$ polarization functions, and the MP2 or CCSD method might be the reason for this observation.

The $B$ and $C$ rotational constants calculated at the MP2/6-311++G(d,p) level of theory are very close to the experimental values. The values obtained from the XIAM and $B E L G I-C_{s}$ fits are similar with deviations within $1 \mathrm{MHz}$. On the other hand, the predicted $A$ rotational constant differs by about $107 \mathrm{MHz}$ and $71 \mathrm{MHz}$ for the $E$ and the $Z$ isomer, respectively. For this parameter, the XIAM and $B E L G I-C_{s}$ programs are not consistent with deviations of 33 and $17 \mathrm{MHz}$ for the $E$ and the $Z$ isomer, respectively, because different parameter sets were fitted (see Table 1 and 2) and the correlations amount these parameters are different. Calculations at the MP2/6-311G(d,p) level of theory match the experimental rotational constants of the $Z$ isomer best, but not those of the $E$ isomer (see Table S-3). On the other hand, the MP2/cc-pVQZ level yields calculated rotational constants which are quite close to the experimental values of the $E$ isomer, but not those of the $Z$ isomer. The predicted barrier heights are in the same order of magnitude as the experimental values, but vary in a wide range from $84 \mathrm{~cm}^{-1}$ to $181 \mathrm{~cm}^{-1}$.

As has been described in ref. 20, we believe that there is an intuitive explanation for the low barrier of the acetyl methyl group in acetates. If we consider the acetate anion (a) illustrated in Figure 6, there is a methyl group with $C_{3 v}$ symmetry attached to the COO frame, which has a perfect $\mathrm{C}_{2 v}$ symmetry due to mesomerism. Therefore, the $V_{3}$ contribution of the potential would be zero, and only a small $V_{6}$ term exists as also found in nitromethane, $\mathrm{CH}_{3} \mathrm{NO}_{2}\left(V_{6}=\right.$ $\left.2.1 \mathrm{~cm}^{-1}\right)^{[21]}$ and toluene $\mathrm{CH}_{3}-\mathrm{C}_{6} \mathrm{H}_{5}\left(V_{6}=4.9 \mathrm{~cm}^{-1}\right)$. ${ }^{[22]}$

In saturated acetates (class I) like ethyl acetate, mesomerism is still possible (Figure 6, (b)) but the frame has no longer $\mathrm{C}_{2 v}$ symmetry. The electronic distribution is slightly out-of-balance, causing a $V_{3}$ potential term of approximately $100 \mathrm{~cm}^{-1}$, which is still small if compared to the situation in ethane where a barrier of $1014 \mathrm{~cm}^{-1}$ is found. [23]

In $\alpha, \beta$-unsaturated acetates (class II), where the ester group shares one plane with the $\mathrm{C}=\mathrm{C}$ double bond, e.g. vinyl acetate (Figure 6, (c)), the mesomeric system is extended from the carbonyl oxygen atom to the $\beta$ carbon atom and increases the double bond character of the carbonyl bond. This is confirmed by the fact that in $\alpha, \beta-$ unsaturated acetates the $\mathrm{CO}$ stretching vibration (vinyl 
acetate: $1762 \mathrm{~cm}^{-1}$, phenyl acetate: $\left.1765 \mathrm{~cm}^{-1}\right)^{[24]}$ is blue shifted with respect to aliphatic acetates (methyl acetate: $1736 \mathrm{~cm}^{-1}$, ethyl acetate: $1728 \mathrm{~cm}^{-1}, n$-propyl acetate: $\left.1724 \mathrm{~cm}^{-1}\right){ }^{[25]}$ We believe that the increase in electronic asymmetry of the COO group is also the reason for a barrier as high as $151 \mathrm{~cm}^{-1}$ in vinyl acetate. Similar arguments hold also for butadienyl acetate (Figure 6, (d)), where a conjugated system of $\pi$ electron is even longer and stretches from the carbonyl oxygen atom to the $\delta$ carbon atom. The experimental barriers of $149 \mathrm{~cm}^{-1}$ and $150 \mathrm{~cm}^{-1}$ for the $E$ and the $Z$ isomer, respectively, are almost the same as that of vinyl acetate $\left(151.492(34) \mathrm{cm}^{-1}\right) .{ }^{[10]}$ Obviously, the torsional barrier of the acetyl methyl group is not affected by increasing the number of conjugated double bonds.

Finally, in $\alpha, \beta$-unsaturated acetates where the ester group and the $\mathrm{C}=\mathrm{C}$ double bond are not in the same plane (class III), mesomerism is not as effective as in the case of a coplanar arrangement. In these cases, barriers between $100 \mathrm{~cm}^{-1}$ and $150 \mathrm{~cm}^{-1}$ are found. Up to now, only two class III molecules, isopropenyl acetate $\left(V_{3}=135 \mathrm{~cm}^{-1}\right)$ and phenyl acetate $\left(V_{3}=138 \mathrm{~cm}^{-1}\right)$, have been studied. In both cases the $\alpha, \beta$ double bonds are tilted by $70^{\circ}$ out of the ester plane. Currently there are not enough data points to give an expression of the barrier height as a function of the tilt angle. This will be subject of our forthcoming investigations.

\section{Conclusion}

The rotational spectra of the $E$ and the $Z$ isomer of butadienyl acetate were investigated using a combination of microwave spectroscopy and quantum chemistry. The most stable conformer of each isomer, which has an effective $C_{s}$ symmetry in both cases, was assigned. The rotational constants, centrifugal distortion constants, and internal rotation parameters were determined with very high accuracy using the programs XIAM and BELGI-Cs. The torsional barriers of both isomers were found to be almost the same as that in vinyl acetate. Therefore, we conclude that additional conjugated double bonds in $\alpha, \beta$-unsaturated acetates do not significantly influence the potential barrier of the acetyl methyl group.

\section{Experimental Section}

The sample of butadienyl acetate was purchased from Sigma Aldrich Chemie $\mathrm{GmbH}$, Munich, Germany, as a mixture of the $E$ and the $Z$ isomer with a stated purity of $95 \%$, and used without further purification. The rotational spectra were recorded using a molecular beam Fourier transform microwave spectrometer operating in the frequency range of 2 to $26.5 \mathrm{GHz}{ }^{[26]}$ A pipe cleaner with a length of $5 \mathrm{~cm}$ was used as substance carrier for several drops of the liquid sample, and was placed in a steel tube upstream the nozzle. A helium stream with a pressure of approximately $200 \mathrm{kPa}$ was set up to flow over the substance.
The mixture of helium and butadienyl acetate was expanded into the cavity.

\section{Acknowledgements}

A.J. thanks the University Paris Diderot for an international mobility grant. V.V. thanks the Fond der Chemischen Industrie (VCl) for a Ph.D. fellowship. Simulations were performed with computing resources granted by JARA-HPC from the RWTH Aachen University under the project jara0124.

Keywords: rotational spectroscopy $\bullet$ conformational analysis • interne rotation $\cdot$ conjugated double bond $\cdot$ ab initio calculations

[1] H. V. L. Nguyen, I. Kleiner, S. T. Shipman, Y. Mae, K. Hirose, S. Hatanaka, K. Kobayashi, J. Mol. Spectrosc. 2014, 229, 17-21.

[2] D.Jelisavac, D. C. Cortés-Gómez, H. V. L. Nguyen, L. W. Sutikdja, W. Stahl, I. Kleiner, J. Mol. Spectrosc. 2009, 257, 111-115.

[3] L. W. Sutikdja, W. Stahl, V. Sironneau, H. V. L. Nguyen, I. Kleiner, manuscript in preparation.

[4] T. Attig, L. W. Sutikdja, R. Kannengießer, I. Kleiner, W. Stahl, J. Mol. Spectrosc. 2013, 284-285, 8-15.

[5] T. Attig, R. Kannengießer, I. Kleiner, W. Stahl, J. Mol. Spectrosc. 2013 290, 24-30.

[6] T. Attig, R. Kannengießer, I. Kleiner, and W. Stahl, J. Mol. Spectrosc., 2014, 298, 47-53.

[7] H. V. L. Nguyen, H. Mouhib, W. Stahl, I. Kleiner, Mol. Phys. 2010, 108 763-770.

[8] H. Mouhib, D. Jelisavac, W. Stahl, R. Wang, I. Kalf, U. Englert, ChemPhysChem. 2011, 12, 761-764.

[9] L. W. Sutikdja, D. Jelisavac, W. Stahl, I. Kleiner, Mol. Phys. 2012, 110, 2883-2893.

[10] H. V. L. Nguyen, A. Jabri, V. Van, W. Stahl, J. Phys. Chem. A 2014, 118, 12130-12136.

[11] B. Velino, A. Maris, S. Melandri, W. Caminati, J. Mol. Spectrosc. 2009, 256, 228-231.

[12] H. V. L. Nguyen, W. Stahl, J. Mol. Spectrosc. 2010, 264, 120-124.

[13] L. Ferres, W. Stahl, H. V. L. Nguyen, to be published.

[14] M. J. Frisch, G. W. Trucks, H. B. Schlegel, G. E. Scuseria, M. A. Robb J. R. Cheeseman, G. Scalmani, V. Barone, B. Mennucci, G. A Petersson, H. Nakatsuji, M. Caricato, X. Li, H. P. Hratchian, A. F. Izmaylov, J. Bloino, G. Zheng, J. L. Sonnenberg, M. Hada, M. Ehara, K Toyota, R. Fukuda, J. Hasegawa, M. Ishida, T. Nakajima, Y. Honda, O. Kitao, H. Nakai, T. Vreven, J. A., Jr. Montgomery, J. E. Peralta, F. Ogliaro, M. Bearpark, J. J. Heyd, E. Brothers, K. N. Kudin, V. N Staroverov, R. Kobayashi, J. Normand, K. Raghavachari, A. Rendell, J. C. Burant, S. S. Iyengar, J. Tomasi, M. Cossi, N. Rega, J. M. Millam, M. Klene, J. E. Knox, J. B. Cross, V. Bakken, C. Adamo, J. Jaramillo, R. Gomperts, R. E. Stratmann, O. Yazyev, A. J. Austin, R. Cammi, C. Pomelli, J. W. Ochterski, R. L. Martin, K. Morokuma, V. G. Zakrzewski, G. A. Voth, P. Salvador, J. J. Dannenberg, S. Dapprich, A. D. Daniels, O. Farkas, J. B. Foresman, J. V. Ortiz, J. Cioslowski, D. J. Fox, Gaussian 09, Revision A.02, Gaussian, Inc., Wallingford CT, 2009.

[15] M. Oki, H. Nakanishi, Bul. Chem. Soc. Japan 1970, 43, 2558-2566.

[16] H. Dreizler, Z. Naturforsch. 1961, 16a, 1354-1367.

[17] H. B. Schlegel, J. Comput. Chem. 1982, 3, 214-218.

[18] H. Hartwig, H. Dreizler, Z. Naturforsch. 1996, 51a, 923-932.

[19] A. C. Fantoni, W. Caminati, R. Meyer, Chem. Phys. Lett. 1987, 133, 27 33.

[20] H. Mouhib, D. Jelisavac, L. W. Sutikdja, E. Isaak, W. Stahl, J. Phys. Chem. A 2011, 115, 118-122. 
[21] G. O. Sørensen, T. Pedersen, H. Dreizler, A. Guarnieri, A. P. Cox, J. Mol. Struct. 1983, 97, 77-82.

[22] H. D. Rudolph, H. Dreizler, A. Saeschke, P. Z. Wendling, Z. Naturforsch. 1967, 22a, 940-944.

[23] R. M. Pitzer, Acc. Chem. Res. 1983, 16, 207-210.

[24] D. Pavia, G. Lampman, G. Kriz, J. Vyvyan, Introduction to Spectroscopy, Cengage Learning, 2014

[25] A. R. Katrizky, J. M. Lagowski, and J. A. T. Beard, Spectrochim. Acta 1960, 16, 964-978.

[26] J.-U. Grabow, W. Stahl, H. Dreizler, Rev. Sci. Instrum. 1996, 67, 4072 4084. 


\section{Entry for the Table of Contents}

\section{ARTICLE}

Effect of $\pi$-conjugation on the methyl torsion: The gas phase structures and internal rotation parameters of butadienyl acetate were determined with very high accuracy by microwave spectroscopy and quantum chemistry for the most energetically favorable conformer of the $E$ and the $Z$ isomer.

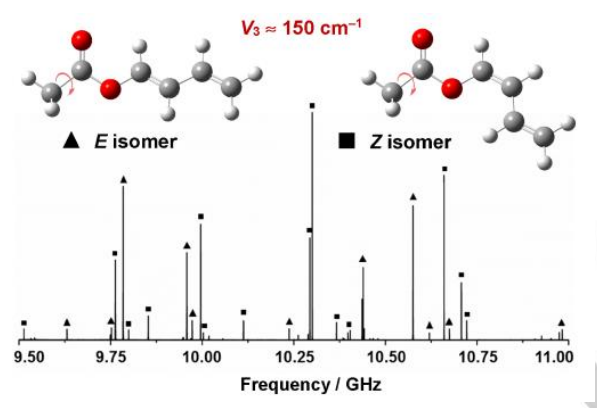

A. Jabri, V. Van, H. V. L. Nguyen, ${ }^{*}$ W. Stahl, I. Kleiner

Page No. - Page No.

Probing the methyl torsional barriers of the $E$ and $Z$ isomers of butadienyl acetate by microwave spectroscopy 